\title{
COLORIMETRIC DETERMINATION OF CEFQUINOME SULPHATE IN BULK AND DOSAGE FORM USING AMMONIUM MOLYBDATE
}

\author{
Shaza Wageialla Shantier and Elrasheed Ahmed Gadkariem \\ Department of Pharmaceutical Chemistry, Faculty of Pharmacy, University of Khartoum, Sudan
}

Received 2013-09-10; Revised 2013-11-10; Accepted 2013-12-20

\begin{abstract}
This study was designed to develop two colorimetric methods for the determination of Cefquinome Sulphate (CS) in bulk and dosage forms using two different concentrations of molybdenum solution. The developed methods were based on the oxidation of CS with $2 \%$ ammonium molybdate, in the presence of sulphuric acid, producing a green colored product with $\lambda_{\max }$ at $409 \mathrm{~nm}$ (Method I) and the oxidation of CS with $10 \%$ ammonium molybdate in acidic media to produce a blue colored product with $\lambda_{\max }$ at $673 \mathrm{~nm}$ (Method II). The factors affecting the color development and stability were optimized and incorporated in the procedure. Beer's law was obeyed over the concentration range $16-80 \mu \mathrm{g} \mathrm{mL}^{-1}$ (Method I) and 40-80 $\mu \mathrm{g} \mathrm{mL}^{-1}$ (Method II) with a correlation coefficient not less than 0.999 . The limit of detection and limit of quantification were 5.7 and $18.9 \mu \mathrm{g} \mathrm{mL}^{-1}$ for Method I, $4.25 \mu \mathrm{g} \mathrm{mL}^{-1}$ and $14.2 \mu \mathrm{g} \mathrm{mL}^{-1}$ for Method II respectively. The average recovery for the dosage form (suspension 2.5\%) was $100.30 \% \pm 0.59 ; \mathrm{n}=3$, which reflected no interference by the suspension excipients. The results obtained by the developed methods for the suspension dosage form were statistically compared with those of a developed HPLC method and evaluated at $95 \%$ confidence limits. The developed methods were proved to be accurate and simple. The methods involved in the study covered, Colorimetric spectrophotometry, High Performance Liquid Chromatography. The molar ratio method is recommended to be conducted in order to determine the reaction stoichiometry.
\end{abstract}

Keywords: Determination, Spectrophotometry, Cefquinome Sulphate, Suspension, Ammonium Molybdate

\section{INTRODUCTION}

Cefquinome Sulphate (CS) is a quinolinium salt (Fig. 1) (Sweetman, 2009). It is a fourth generation cephalosporine and has a broad spectrum activity against Gram-positive and Gram-negative bacteria. It is used for the treatment of bovine respiratory disease (FDA, 2006).

In literature, methods used for analysis of CS include chromatographic methods either in animals' biological fluids (Uney et al., 2010; Xie et al., 2013; Sukren and Knappstein, 2003; Parlevliat et al., 2009) or in dosage form (Janaki and Appala, 2012). Recently, we developed stability-indicating spectrophotometric and HPLC methods for the determination of CS in bulk and dosage form (Shantier and Gadkariem, 2013).

Literature review revealed no previous colorimetric methods had been adopted for the assay of CS in its dosage forms.

It is well known that reduction of acidified molybdenum produces a colored solution which was utilized in analytical chemistry. Salts of Mo (VI) had been used as oxidizing agents for determination of various drugs: Tetracycline (Saleh, 1986), chlorampenicol (Morelli, 1987), cephalosporines (Prodromas, 1988a) and levodopa (Prodromas, 1988b). Spectrophotometry continues to be very popular, because of its simplicity and the general low operational cost compared to the recently developed sophisticated instrumental methods.

Corresponding Author:Shaza Wageialla Shantier, Department of Pharmaceutical Chemistry, Faculty of Pharmacy, University of Khartoum, Sudan Tel: +249 12637509 
<smiles>CO/N=C(\C(=O)N[C@H]1C(=O)N2C(C(=O)O)=C(C[n+]3cccc4c3CCCC4)CS[C@H]12)c1csc(N)n1</smiles>

Fig. 1. Chemical structure of cefquinome sulphate

Therefore, the aim of the present work is to develop simple colorimetric methods for the determination of CS in bulk and dosage form that can be useful for routine quality control of the drug.

\section{MATERIALS AND METHODS}

\subsection{Instrumentation}

UV spectrophotometric studies were carried out on Shimadzu UV-1800ENG240V, (Koyoto, Japan).

\subsection{Materials}

All materials and reagents used were of analytical grade.

Drug sample $\left(\right.$ Cobactan $\left.^{\circledR}, 2.5 \%\right)$ was kindly provided by Intervet Schering-Plough, European Union. The reference standard was provided by Intervet International $\mathrm{GmbH}$.

CS standard stock solution was freshly prepared to obtain $800 \mu \mathrm{g} \mathrm{mL} \mathrm{mL}^{-1}$ (solution A) and $500 \mu \mathrm{g} \mathrm{mL}$ (solution B). Sulphuric acid $\mathrm{H}_{2} \mathrm{SO}_{4} \quad(\mathrm{Sd}$ fine Chem.Limited, Mumbai): $3 \mathrm{M}$ and upto $11 \mathrm{M}$ were prepared in the usual way from the concentrated acid (98\%). Ammonium molybdate $\left((\mathrm{NH} 4)_{6} \mathrm{Mo}_{7} \mathrm{O}_{24} \cdot 4 \mathrm{H}_{2} \mathrm{O}\right.$; Sd fine Chem. Limited, Mumbai): Solutions were freshly prepared by dissolving $0.5 \mathrm{~g}$ in $25 \mathrm{~mL}$ distilled water to obtain $2 \% \mathrm{~m} / \mathrm{v}$ (Mo-1) and dissolving $2.5 \mathrm{~g}$ in $25 \mathrm{~mL}$ of $50 \% \mathrm{v} / \mathrm{v} \mathrm{H}_{2} \mathrm{SO}_{4}$ to obtain $10 \% \mathrm{~m} / \mathrm{v}(\mathrm{Mo}-2)$.

\subsection{Procedure Calibration Graph}

\subsubsection{Method I}

Different accurately measured volumes (100-500 $\mu \mathrm{L})$ of solution A were transferred into five stoppered glass tubes. $1 \mathrm{~mL}$ of Mo-1 solution was added to each tube, followed by $3 \mathrm{~mL}$ of $9 \mathrm{M} \mathrm{H}_{2} \mathrm{SO}_{4}$. The tubes were then heated in a boiling water bath for $30 \mathrm{~min}$. After cooling, the volumes were completed to $5 \mathrm{~mL}$ with distilled water. The blank was prepared in the same manner using distilled water instead of CS solution. The absorbance was measured at $409 \mathrm{~nm}$ and calibration graph was constructed by plotting the absorbance values against the drug concentrations series.

\subsubsection{Method II}

Different accurately measured volumes (400-800 $\mu \mathrm{L})$ of solution B were transferred into five stoppered glass tubes. About $1 \mathrm{~mL}$ of Mo-2 solution was added to each tube, followed by $3 \mathrm{~mL}$ of $7 \mathrm{M} \mathrm{H}_{2} \mathrm{SO}_{4}$. The tubes were then heated in a boiling water bath for $15 \mathrm{~min}$. After cooling, the volumes were completed to $5 \mathrm{~mL}$ with distilled water. The blank was prepared in the same manner using distilled water instead of CS solution. The absorbance was measured at $673 \mathrm{~nm}$ and calibration graph was constructed by plotting the absorbance values against the drug concentrations series.

\subsection{Procedure for the Assay of CS Suspension}

CS sample solutions were freshly prepared to obtain $800 \mu \mathrm{g} \mathrm{mL}^{-1}$ (solution C) and $500 \mu \mathrm{g} \mathrm{mL}^{-1}$ (solution D) using water as diluents.

About $300 \mu \mathrm{L}$ of solution $\mathrm{C}$ and $600 \mu \mathrm{L}$ of solution $\mathrm{D}$ were treated as under calibration graph. The concentration of both sample solutions (C and D) were obtained from the regression analysis data of the standard absorbance/concentration plot.

\section{RESULTS AND DISCUSSION}

The cephalosporins are among the widely used antibiotics for the treatment of bacterial infections in humans and animals. CS, one of these $\beta$-lactam cephalosporines, is the target of the present work. It has a free amino group and expected to undergo oxidationreduction reaction.

It is well known that a colored solution is obtained as a result of the reduction of acidified molybdenum (Mo (VI)) solution. It has several oxidation states, the most stable being +4 and +6 . The highest oxidation state is common in the molybdenum (VI) trioxide $\left(\mathrm{MoO}_{3}\right)$. When $\mathrm{MoO}_{3}$ is dissolved in neutral or alkali solution the simple $\mathrm{MoO}_{4}{ }^{2-}$ anion is produced which gives upon reduction the hydroxide $\mathrm{MoO}(\mathrm{OH})_{2}$ (green colour). As the $\mathrm{pH}$ is reduced the first species to be formed is the heptamolybdate (Pope and Muller, 1997). 
The developed methods involved the reaction of CS with Mo-1 solution, in acidic media, to produce a green product with a wavelength maximum at $409 \mathrm{~nm}$ and with Mo-2 solution to produce a blue colored product at $\lambda_{\max }$ $673 \mathrm{~nm}$ (Method I and II) respectively (Fig. 2).

It is proposed that the reaction between CS and molybdenum could be through a charge-transfer reaction (metal/ligand) leading to the observed lambda shift into the visible region $(409,673 \mathrm{~nm})$ depending on the molybdenum state.

\subsection{Optimization of Different Experimental Parameters}

The optimum conditions were established based on the maximum color intensity and the stability of the reaction product.

\subsection{Effect of Sulphuric Acid Concentration}

The concentration and volume of suphuric acid is one of the important parameters affecting the oxidationreduction reaction. Different concentrations of the acid upto $11 \mathrm{M}$ were investigated.

For method I, the maximum color intensity with good linearity and stability was obtained using $9 \mathrm{M}$ $\mathrm{H}_{2} \mathrm{SO}_{4}$. At lower concentration, the color was not obtained which indicates that the reaction product was not formed; while at higher concentrations (11 M), although it gives more intense color, the color stability and the linearity were decreased, (Table 1 and Fig. 3). Other acids such as acetic acid and $\mathrm{HCl}$ were also studied. It was found that either no color reaction was produced with acetic acid or a light color was obtained with hydrochloric acid which was unstable.

For method II, the maximum color intensity with good linearity and stability was obtained using $7 \mathrm{M}$ $\mathrm{H}_{2} \mathrm{SO}_{4}$. The color intensity increased gradually with increasing sulphuric acid concentration upto $7 \mathrm{M}$ sulphuric acid, then started to decrease when using higher acid concentrations (9 and $11 \mathrm{M}$ ). Therefore, $7 \mathrm{M}$ sulphuric acid was found to be optimum to produce stable and intense color (Table 2 and Fig. 4).

The effect of different volumes of $\mathrm{H}_{2} \mathrm{SO}_{4}$ was also investigated. About $3 \mathrm{~mL}$ of the acid was found to be sufficient for color production and stability.

\subsection{Effect of Ammonium Molybdate Concentration}

Ammonium molybdate was used as color producing reagent. The adopted concentrations and volume, $1 \mathrm{~mL}$ of $2 \%$ solution (Method I) and $1 \mathrm{~mL}$ of $10 \%$ solution (Method II), were sufficient for maximum absorbance values and stability. Below or above these concentrations and volume, the absorbance was found to decrease.

\subsection{Effect of Heating Time}

The heating time was one of the important parameters studied for proper color development. The results obtained showed that heating in boiling water bath for 45 and $30 \mathrm{~min}$, for method I and II respectively, gave higher absorbance but the color stability was decreased. Below $30 \mathrm{~min}$ (method I) and $15 \mathrm{~min}$ (method II), the reaction products were not completely formed. Therefore, heating for 30 and $15 \mathrm{~min}$. (method I and II respectively) was found to be the optimum condition to develop an intense and stable color.

Also, the order of addition of the reactants recommended in the general procedure was found important for the development of a color with maximum intensity and stability.

The formed products were found to remain stable for at least $3 \mathrm{~h}$ (Method I) and $24 \mathrm{~h}$ (Method II).

\subsection{Analytical Curves, Recovery and Precision}

The optimized conditions were utilized to construct the calibration graphs using authentic CS. Beer's law plots were obeyed for drug concentrations within a range of $16-80 \mu \mathrm{g} \mathrm{mL}^{-1}$ (Method I) and 40-80 $\mu \mathrm{g} \mathrm{mL}^{-1}$ (Method II). Spectral data for the reaction of molybdate with CS are presented in Table 3.

The low values of the standard errors of the slope, the intercept and correlation coefficient values (not less than 0.999) reflected the consistency of the prepared calibration graphs.

The accuracy of the procedure and freedom of interference by the suspension excipients were confirmed by the results obtained for recovery testing of added amount of authentic CS to suspension solution in the ratio of $1: 1$. The results showed good recovery $(100.30 \% \pm 0.59, \mathrm{n}=3)$.

To examine the repeatability and reproducibility of the methods, replicate determinations $(n=3)$ were made for four different concentrations of the standard curve. The calculated RSD values were found to be within the accepted limits (less than $2 \%$ ).

Table 1. Effect of sulphuric acid concentration (Method I)

\begin{tabular}{llllll}
\hline Sulpuric acid conc & $3 \mathrm{M}$ & $5 \mathrm{M}$ & $7 \mathrm{M}$ & $9 \mathrm{M}$ & $11 \mathrm{M}$ \\
\hline Absorbance & & & & & \\
$\left(60 \mu \mathrm{g} \mathrm{mL}^{-1}\right)$ & 0 & 0 & 0.116 & 0.283 & 0.395 \\
Correlation coefficient & - & - & - & 0.999 & 0.987 \\
\hline
\end{tabular}

Table 2. Effect of sulpuric acid concentration (Method II)

\begin{tabular}{llllll}
\hline Sulphuric acid conc & $3 \mathrm{M}$ & $5 \mathrm{M}$ & $7 \mathrm{M}$ & $9 \mathrm{M}$ & $11 \mathrm{M}$ \\
\hline Absorbance $\left(100 \mu \mathrm{g} \mathrm{mL}^{-1}\right)$ & 0 & 0.117 & 0.503 & 0.21 & 0.058 \\
\hline
\end{tabular}


S.W. Shantier and E. Ahmed Gadkariem / American Journal of Applied Sciences 11 (2): 202-206, 2014

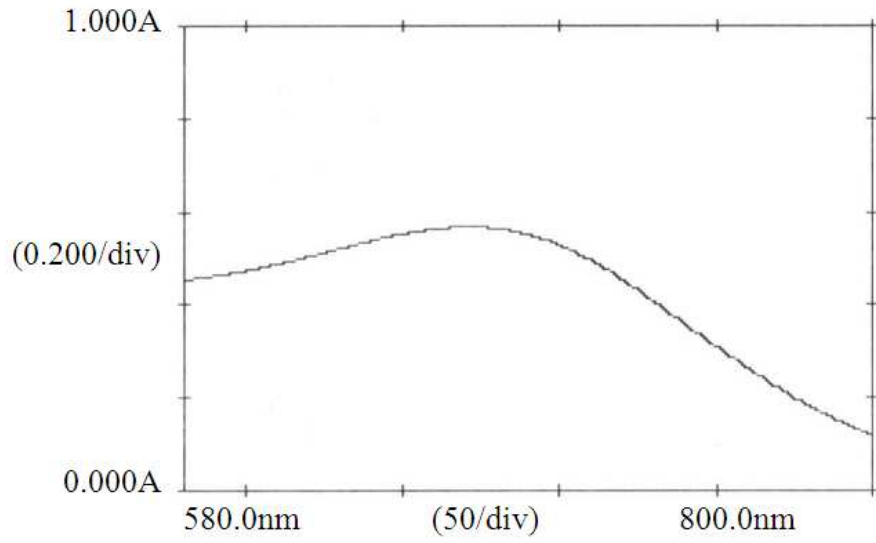

Fig. 2. UV/VIS spectrum of the colored product (673nm)

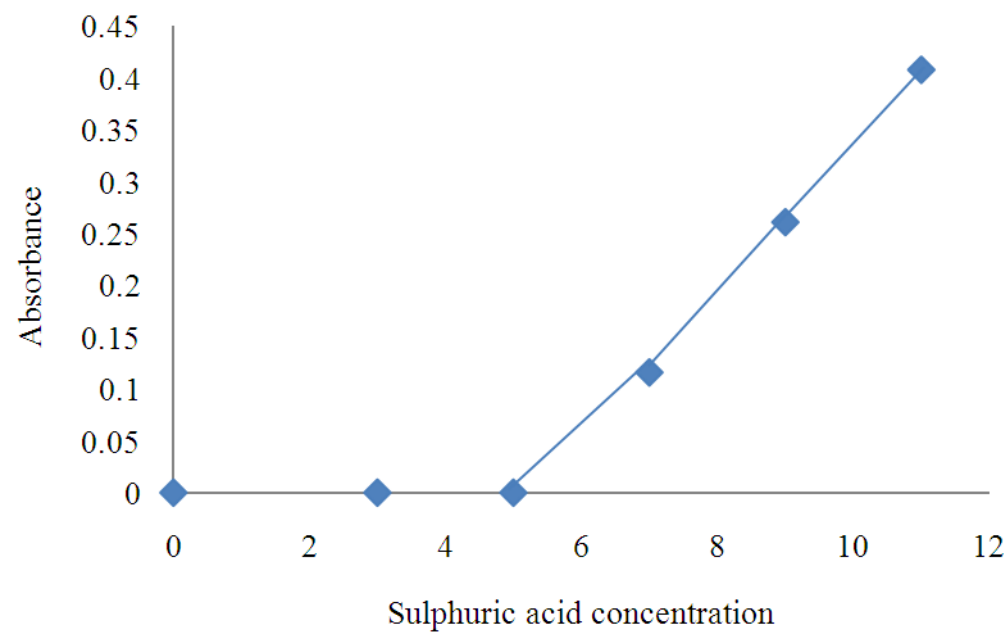

Fig. 3. Effect of sulphuric acid concentration on the color intensity

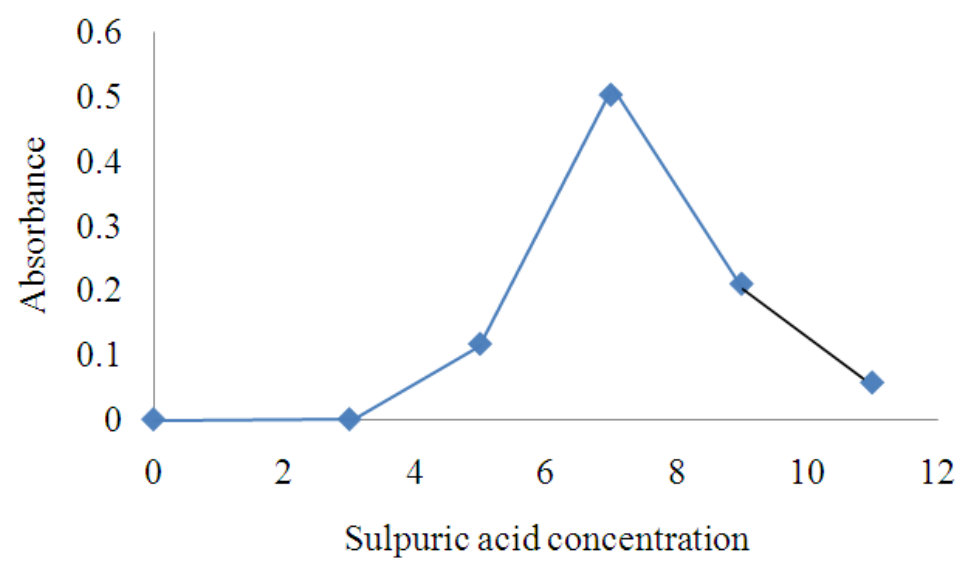

Fig. 4. Effect of sulphuric acid concentration on the color intensity 
Table 3. Spectral data of the reaction of CS with ammonium molybdate

\begin{tabular}{lll}
\hline Parameter & Method 1 & Method 2 \\
\hline Slope $\pm \mathrm{SE}^{*}$ & $0.004 \pm 0.00048$ & $0.0033 \pm 0.00047$ \\
Intercept $\pm \mathrm{SE}^{*}$ & $-0.0014 \pm 0.026$ & $-0.00058 \pm 0.029$ \\
Correlation coefficient & 0.999 & 0.999 \\
Range & $16-80 \mu \mathrm{g} \mathrm{mL}^{-1}$ & $40-80 \mu \mathrm{g} \mathrm{mL}^{-1}$ \\
$\mathrm{LOD}$ & $5.7 \mu \mathrm{g} \mathrm{m}^{-1}$ & $4.25 \mu \mathrm{gL} \mathrm{m}^{-1}$ \\
LOQ & $18.9 \mu \mathrm{g} \mathrm{mL}^{-1}$ & $14.2 \mu \mathrm{g} \mathrm{mL}$ \\
Molar absorbitivity & & \\
$\left(\mathrm{L} \mathrm{mol} \mathrm{cm}^{-1}\right)$ & 2185 & 1715 \\
\hline *Standard error calculated at $95 \%$ confidence limit
\end{tabular}

Table 4. Validation results of developed method compared to the developed HPLC method

\begin{tabular}{lcll}
\hline & Content\% of & & $* \mathrm{~F} \mathrm{cal}$, \\
& $\mathrm{CS} \pm \mathrm{RSD} \%$ & $* \mathrm{t}$ cal, $\mathrm{t}(\mathrm{tab})$ & $\mathrm{F}(\mathrm{tab})$ \\
\hline Method I & $101.00 \pm 0.64$ & $0.78,(2.78)$ & $7(19)$ \\
Method II & $102.00 \pm 0.83$ & $1.44,(2.78)$ & $5(19)$ \\
$\begin{array}{l}\text { Liquid } \\
\text { chromatographic method }\end{array}$ & $100.00 \pm 1.87$ & - & \\
\hline$*=\mathrm{t}$ and F calculated and tabulated & & \\
\end{tabular}

The methods were applied for the drug uniformity testing in CS suspension (2.5\%) where good assay results $(X \pm \operatorname{RSD}(\%), n)$ were obtained.

The validity of the developed methods for the determination of cefquinome in bulk or dosage form was assessed by comparison of the statistical results obtained with those of the developed HPLC method (Shantier and Gadkariem, 2013). Data of Table 4 show the obtained assay results and the calculated t-and F-values as compared to the corresponding tabulated values at $95 \%$ confidence level. As the calculated t-and F-values were less than tabulated ones, this indicates very good accuracy and precision of the developed methods.

\section{CONCLUSION}

The proposed methods are simple, sensitive, accurate, precise and inexpensive analytical techniques for the determination of CS in bulk and dosage form. Statistical comparison of the results with the developed HPLC method indicates no significant difference at $95 \%$ confidence limit. The proposed methods are the only colorimetric methods for the determination of CS in its dosage form. They have low operational cost compared to the chromatographic methods. Another advantage of the proposed methods is that there is no need for pretreatment of the sample (extraction step).

\section{REFERENCES}

FDA, 2006. Risk estimation for cefquinome to evaluate potential microbiological effects on bacteria of human health concern.

Janaki, P.P. and R.G. Appala, 2012. Estimation of cefquinome sulphate in suspension form by RPHPLC. Asian J. Pharmaceutical Anal., 2: 33-35.

Morelli, B., 1987. Spectrophotometric assay for chloramphenicol and some derivatives in the pure form and in formulations. J. Pharmaceutical Biomed. Anal., 5: 577-583. PMID: 16867480

Parlevliat, J.M., D.L. Paccamonti and S.A. Barker, 2009. Cefquinome concentrations in endometrium after intrauterine treatment of cobactan $4.5 \%$ in mares and inflammatory response of the endometrium to this treatment. Reproduct. Domest. Anim., 44: 189193. PMID: 18992083

Pope, M.T. and A. Muller Achim, 1997. Polyoxometalate chemistry: An old field with new dimensions in several disciplines. Angewandte Chemie Int., 30: 34-48. DOI: 10.1002/anie.199100341

Prodromas, B.I., 1988a. Spectrophotometric determination of certain cephalosporines using molybdophosphoric acid. Analyst, 113: 1083-1086. DOI: 10.1039/AN9881301083

Prodromas, B.I., 1988b. Spectrophotometric determination of levodopa with ammonium molybdate. Analytica, 113: 1083-1083.

Saleh, M.S., 1986. Spectrophotometric determination of tetracycline with sodium molybdate. Analytica, 111: 97-99. PMID: 3954055

Shantier, S.W. and E.A. Gadkariem, 2013. Spectrophotometric and HPLC methods for determination of cefquinome sulphate in bulk and dosage form. Elixir Pharmacy, 59: 15471-15473.

Sukren, G. and K. Knappstein, 2003. Detection of cefquinome in milk by liquid chromatography and screening methods. Analyt. Chim. Acta, 483: 363372. DOI: $10.1016 / \mathrm{S} 0003-2670(02) 01473-3$

Sweetman, S.C., 2009. Martindale: The Complete Drug Reference. 36th Edn., Pharmaceutical Press, ISBN10: 0853698406, pp: 3694.

Uney, K., F. Altan and M. Elmas, 2010. Development and validation of HPLC method for determination of cefquinome sulphate in sheep plasma. Antimicrobial Agents Chemotherapy, 55: 854-859. DOI: 10.1128/AAC.01126-10

Xie, W., X. Zhang, T. Wang and S. Du, 2013. Pharmacokinetic analysis of cefquinome in healthy chickens. Br. Poult. Sci., 54: 81-86. PMID: 23444857 